\title{
Smallholder Farmers' Perceptions on Climate Change and the Use of Sustainable Agricultural Practices in the Chinyanja Triangle, Southern Africa
}

\author{
Clifton Makate ${ }^{1, *}$, Marshall Makate ${ }^{2}$ and Nelson Mango ${ }^{3}$ \\ 1 UN Environment-Tongji Institute of Environment for Sustainable Development, Tongji University, \\ Shanghai 200092, China \\ 2 Department of Economics, State University of New York at Albany (SUNY Albany), Albany, NY 12222, USA; \\ mmakate@albany.edu \\ 3 International Center for Tropical Agriculture (CIAT), Kawanda Research Station, Kampala 920102, Uganda; \\ n.mango@cgiar.org \\ * Correspondence: ruumakate@live.com
}

Academic Editors: Frank Witlox and Martin J. Bull

Received: 1 November 2016; Accepted: 28 February 2017; Published: 15 March 2017

\begin{abstract}
In developing regions with high levels of poverty and a dependence on climate sensitive agriculture, studies focusing on climate change adaptation, planning, and policy processes, have gained relative importance over the years. This study assesses the impact of farmer perceptions regarding climate change on the use of sustainable agricultural practices as an adaptation strategy in the Chinyanja Triangle, Southern Africa. In this empirical approach, we adopt methods that account for the plausibility that unmeasured characteristics exist, which are correlated with perceptions and the adoption of Sustainable Agricultural Practices. We use a unique and representative dataset collected in December 2012 and June 2013, from smallholder farmers in the Chinyanja Triangle. The results indicate that farmer's perceptions significantly influence the use of sustainable agricultural practices. Specifically, we established that farmer perceptions considerably impact the use of grain legume rotations, inorganic fertilizers, compost, and farmyard manure. Our results highlight the need for a serious and perhaps equal consideration of farmer perceptions regarding climate change, as important inputs to climate change adaptation policies targeted at enhancing climatic resilience in smallholder farming communities. This is plausible as the adaptation and pliability of farmers to the effects of climate change should be a social process involving the collective efforts from various stakeholders.
\end{abstract}

Keywords: climate change adaptation; farmer perceptions; sustainable agriculture practices (SAPs); impact; Southern Africa

\section{Introduction and Background}

This paper sought to investigate smallholder farmers' perceptions on climate change and their responses, through the adoption of sustainable agricultural practices (SAPs) in the Chinyanja Triangle, Southern Africa. The way in which individuals (including farmers) and societies respond to climate change has been closely linked to community perceptions of climate variability, as well as other consequences [1-3]. As such, a lucid understanding of smallholder farmers' perceptions regarding climate variability, and how they influence their farming practices, is of critical importance.

Climate change and agriculture have a unique relationship, which is well documented in the literature [1-3]. This particularly prevalent with regards to its influence on agricultural activities and subsequent crop yields. There is growing evidence to suggest that climate change is real and has 
potentially devastating consequences on humanity [4]. Climate variability and change affect humanity through higher than normal average temperatures, altered patterns and intensity of precipitation, mid-season droughts, and flooding [5-7]. However, greenhouse gas emissions from the region's smallholder farming sector are expected to be low, considering that their farming systems are not highly mechanized [8].

Smallholder farmers are more likely to be influenced by climate change $[9,10]$, given their limited adaptive capacity [5]. Some of the challenges inflicted by climate change include the impacts on the ecosystem, agricultural production, and livelihoods [11,12]. Also, climate change elevates vulnerability and reduces resilience in regions dominated by poverty, subsistence food production, and land degradation problems [13]. In other words, climate change poses a huge threat to the sustainability of food production and other livelihood activities in vulnerable African communities.

Building resilience to climate change is one key factor that can lessen the future impacts of climate change in Africa. Adaptation can reduce the intensity of the future impacts of climate change on crop yields and livelihoods [10]. Adger et al. [14] insinuate that, without adaptation, climate change will significantly affect the agricultural sector [14,15]. However, in Waha et al. [16], it is clearly stated that an adaptation to climate change can soften the impacts of agriculture. Nevertheless, the efficient use of SAPs can offer viable solutions to some of the challenges induced by climate change in the agricultural sector. Previous studies suggest that an effective adoption of SAPs potentially alleviates some of the many problems posed by climate change and variability, through a reduction in land degradation, and an improvement in crop yields and livelihoods [17-21]. Thus, SAPs possess the potential to significantly contribute towards climate change adaptations in smallholder farming communities.

Formally defined, SAPs are the agricultural practices enabling farmers to meet current and future societal needs for food, fiber, ecosystem services, and healthy lives [22]. Through the adoption of SAPs, farmers can potentially maximize the net societal benefits (economic, social, and environmental) [22]. Therefore, it implies that SAPs at the farm level may include various conservation practices, including Integrated Soil Fertility Management (ISFM) ${ }^{1}$ [23]. According to Vanlauwe et al. [24], ISFM is an essential component of sustainable intensification in the scarce nutrient environments of sub-Saharan Africa. However, perceptions regarding climate change can play an essential role in influencing adaption measures such as SAPs. This is because, at the individual farmer level, adaptation behaviours in response to climate change may be influenced by attitudes and knowledge of climate change $[25,26]$. As such, this paper tries to investigate whether there is a relationship between perceptions on climate change and adaptation through the use of sustainable agricultural practises.

A study by Simelton et al. [27] contends that increasing a farmer's adaptive capacity, intensification, and adaptation strategies, should be coordinated and linked to the farmer's understanding of the exposure to risk, which makes farmers' perceptions of climate variability indispensable. The literature on adaptation also suggests that perceptions related to climate change are necessary prerequisites for adaptation [27-29]. Farmer perceptions on climate change are an important determinant of the type of management style adopted by the farmer [30]. Furthermore, individuals' appreciation of the veracity of climate change, degree of worry about climate change impacts, and opinions on the personal and wider responsibilities for addressing the impacts of climate change, have been shown to be important in influencing climate action [31-34]. As such, farmers' knowledge about climate change, and how it relates to use of SAPs, is critically important. Therefore, this means that farmers' perceptions must be well-integrated into the adaptation strategies available to the farmer, in order to improve the adaptive capacity of the farmer and the effectiveness of the strategies adopted. Community awareness of climate change is even more important in affecting adaptations to climate change, as illustrated by Adger [15], who insinuates that the effectiveness of adaptions to climate change partly depend on the social

1 ISFM is defined as a set of soil fertility management practices that necessarily include the use of fertilizer, organic inputs, and improved germplasm, combined with the knowledge on how to adapt these practices to local conditions, aimed at maximizing the agronomic use efficiency of the applied nutrients and improving crop productivity [23]. 
acceptability of climate change adaptation options, amongst other factors [15]. However, very little is known regarding a farmer's perceptions on climate change [27], and how these perceptions relate to the adoption of SAPs in Southern Africa. The focus of previous longitudinal studies using meta data analysis has been on the link between farmers' perceptions on climate change and meteorological data $[10,28,29,35,36]$. Southern Africa is one of the regions projected to be worst affected by climatic changes [37]. The previous literature in agricultural economics suggests numerous ways through which climate change impacts the lives of people in Southern Africa [4,5,38,39].

A farmer's perceptions of climate change might strongly influence the decision to adopt different SAPs. This study examined the role played by perceptions on the adoption of SAPs in the Chinyanja Triangle, which is located in three Southern African countries, namely; Zambia, Mozambique, and Malawi, and draws policy implications for climate change adaptations in the region.

\section{Research Methodology}

\subsection{Study Site Description}

This research was conducted in the Chinyanja Triangle situated in Southern Africa (SA) (see Figure 1 below). The Chinyanja Triangle is principally composed of the eastern province of Zambia $\left(15^{\circ} 00^{\prime} \mathrm{S}\right.$ and $\left.30^{\circ} 00^{\prime} \mathrm{E}\right)$, southern and central regions of Malawi $\left(13^{\circ} 30^{\prime} \mathrm{S}\right.$ and $\left.34^{\circ} 00^{\prime} \mathrm{E}\right)$, and the Tete province of Mozambique $\left(18^{\circ} 15^{\prime} \mathrm{S}\right.$ and $\left.35^{\circ} 00^{\prime} \mathrm{S}\right)$ (Figure 1). It has three distinct eco-zones with plateaus on the northern end, sub-humid escarpments around the center, and the semi-arid Shire, Luangwa, and Zambezi, river valleys towards the south [40]. According to Amede et al. [41], the Chinyanja Triangle is dominated by Nyanja people that share language dialects, similar beliefs, and history, suggesting similarities in the approaches to resource utilization, and more importantly, in land management. Their farming cultural repertoire is the same [42,43]. Land use rights within the Chinyanja Triangle are similar, and chiefs are the custodians within the jurisdiction of their chiefdoms. This region forms a triangular shape and has Chichewa as the common mother language of the inhabitants, hence it is nicknamed the Chinyanja Triangle. The Chinyanja Triangle concept was initiated by the World Agroforestry Centre (ICRAF) to serve this cohesive group of people with improved and sustainable agricultural practices, taking advantage of linguistic-based similarities, and the collective spirit for agricultural development given the ease of communication through traditional linkages. Within the Chinyanja Triangle, dryland agriculture is the predominant source of livelihood, for over $90 \%$ of the rural population [44]. The agricultural practice in the Chinyanja Triangle is predominantly crop production, mainly comprised of maize, groundnut, sorghum, and millet production. Precisely, the Chinyanja Triangle region has three overlapping farming systems. First, the Chinyanja Triangle focuses on maize, cassava, and a beans-fish-based farming sub-system, which is the predominant system, and is mostly located on the northern side of the Zambezi River. In this sub-system, farmers produce maize and cassava as major crops, mainly intercropped with beans and other legumes. Aquaculture is gaining popularity as it is being promoted and supported by international donors and non-governmental organisations [45]. Second, there is a specific focus on the sorghum, millet, livestock sub-system, which is predominant in the semi-arid environments. Sorghum and millet are the crops which are mainly grown in this particular sub-system, with potato and pigeon pea amongst the other cropping options. Cattle and goats are also an important part of this sub-system and serve as a means to overcome droughts [40]. This sub-system includes the semi-arid districts of Katete in the eastern province of Zambia, the Mwanza and Ntcheu districts of Malawi, and the Macanga and Moatize districts in the Tete province of Mozambique. Third, the Chinyanja Triangle area also concentrates on a farming sub-system based on livestock production, which is mostly popular in the driest parts of the region, which is predominantly covered by savannah grasses and desert bushes. Livestock production dominates the livelihood in this sub-system, but sorghum and millet are also grown in this sub-system [40]. According to Frenken and Jean-Marc [43], approximately 20\%, $76.4 \%$, and $91.5 \%$ of the total land area of Mozambique, Zambia, and Malawi, respectively, are within 
the Zambezi River Basin where the Chinyanja Triangle is located [40,43]. Also, the population density is variable within the Chinyanja Triangle, with estimates averaging 148, 27, and 30 persons per square kilometre in Malawi, Mozambique, and Zambia, respectively. For more on the historical development and characteristics of the Chinyanja Triangle, readers can view Amede et al. [40]. The data analysed in the present study is representative of selected sites within the Chinyanja Triangle from which the data was collected (See Figure 1).

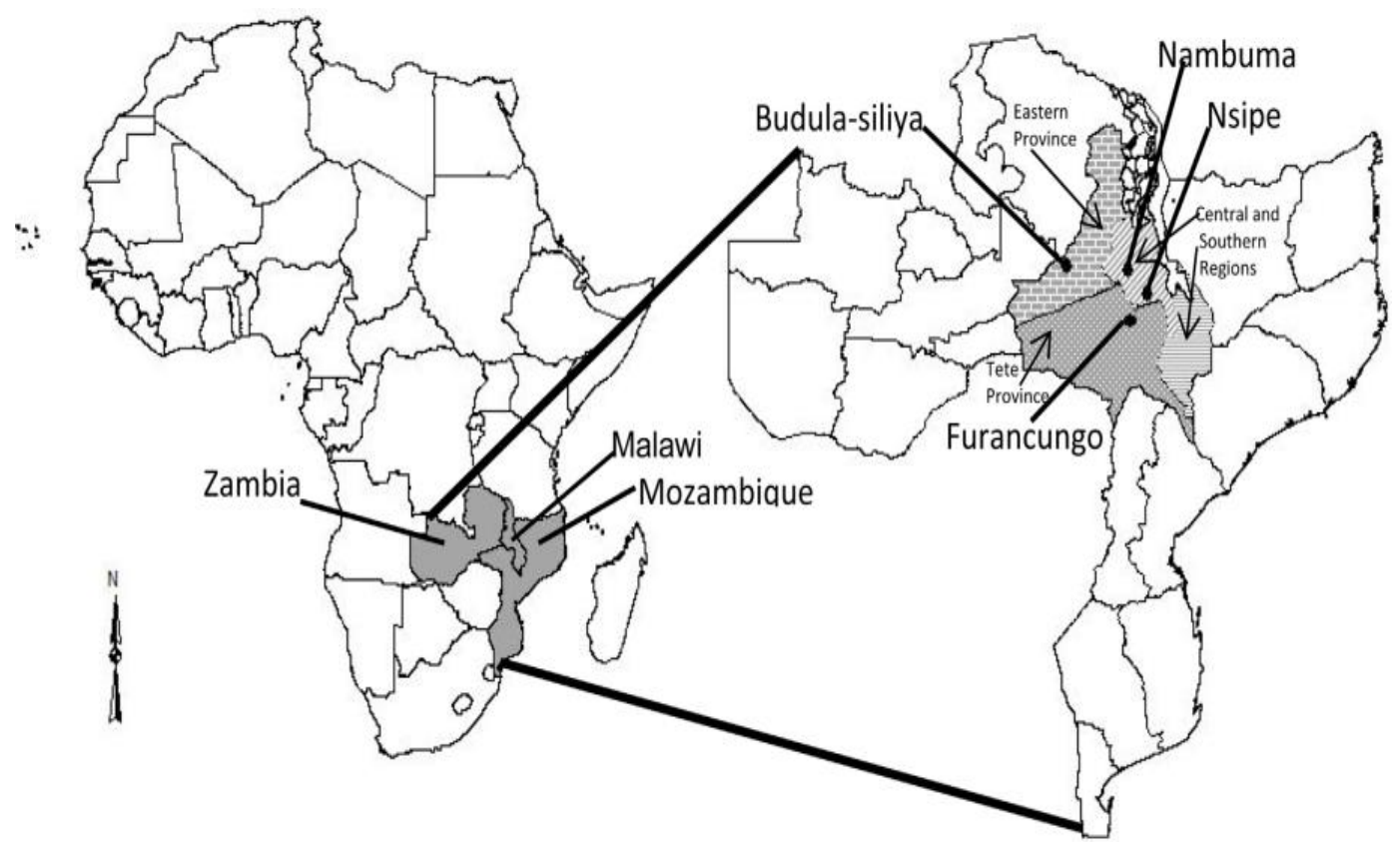

Figure 1. Map showing the Chinyanja Triangle, covering the Tete province of Mozambique, the Eastern province of Zambia, and the Central region of Malawi. Reproduced from Mponela et al. [42] with permission from Elsevier, 2016. Specific coordinates (latitude, longitude) for the specific study sites shown, are as follows; Budula-Siliya $\left(13.7567^{\circ} \mathrm{S}, 31.9566^{\circ} \mathrm{E}\right)$, Nambuma $\left(13.7035^{\circ} \mathrm{S}, 33.5976^{\circ} \mathrm{E}\right)$, Nsipe (14.1832 $\left.{ }^{\circ} \mathrm{S}, 34.1254^{\circ} \mathrm{E}\right)$, Furacungo $\left(14.9114^{\circ} \mathrm{S}, 33.6232^{\circ} \mathrm{E}\right)$.

\subsection{Sampling Design}

The study made use of the project sites of the Consultative Group for International Agricultural Research (CGIAR), Research Program on Dryland Systems and Africa RISING projects in Mozambique, Malawi, and Zambia. Data were collected in four regions; the Tete province of Mozambique, the Eastern province of Zambia, and the central and southern regions of Malawi. Four sites in each of the regions within the Chinyanja Triangle make up the sample data. The specific sites from which data were collected include Furancungo in the Tete province of Mozambique, Msoro in the Eastern province of Zambia, and Linthipe and Nsipe in the central and southern regions of Malawi. Within each site, there are 16 clusters. For the Africa Rising sites, the two mother trials (established during 2012/13 growing season) were used as center clusters, with the other 14 clusters randomly spread around them. Each cluster covers an area of about two square kilometers with 10 randomly located sampling plots, from where the Land Condition Survey (LCS) was conducted. For each cluster, five farmers owning odd numbered plots $(1,3,5,7$, and 9) were considered for household interviews on socioeconomic attributes. The socioeconomic data were collected from the owners of the plots sampled during the LCS, thereby geo-referencing farmers to their sampled plots and not the place of residence. Plot owners were identified during the LCS by a local person taken from the nearest village. Data were collected using structured questionnaires and the information gathered included: the socio-demographic characteristics of the households; resource endowments; crop production; climate change and variability perceptions; use of ISFM practices; various land, soil, and water conservation 
practices; and other sustainable agricultural practices. Data was collected between December 2012 and June 2013, with the help of extension service personnel, agricultural research officers, and trained enumerators. A total of 312 questionnaires were gathered and used for data analysis.

\subsection{Key Variables Measuring Climate Change Perceptions}

We rely on three variables to measure the respondent's perceptions on climate change. A general question was asked, to determine what the respondent felt about climate change (Do you think climate has changed over time? $(1=$ yes; $0=$ no)). We used the responses to this question to measure the general perception of the respondent when considering climate change. A follow up question was then asked to the respondent, to present evidence on the changes which they had experienced in the recent past (What evidence can you sight, or what happened with climate change? Give two events: 1 = temperature increased; 2 = temperature decreased; $3=$ rainfall decreased; 4 = rainfall increased; $5=$ Change of rainfall patterns; $6=$ Change in cropping season; $7=$ Change in type of crops grown; $8=$ Rivers have dried; and $9=$ other (specify)). We then used the two most common events cited as evidence of having perceptions on specific climatic changes. Temperature increase and rainfall increase were the two most common events cited.

\subsection{Model Specification and Data Analysis}

The objective of our analysis is to relate farmers' perceptions of climatic change and variability in their region, and the use of SAPs as an adaptation strategy in farming. We build our analysis in this study from the utility maximization framework outlined in Rahm and Huffman [46]. In this context, farmers compare the net intended benefits derived from adopting each SAP available to them, and choose the alternatives as a combination that yields the highest utility. This framework has also been used in previous related studies [47-49]. Our empirical approach differs slightly from the mentioned studies, in that we assess the role of perceptions on the adoption of selected SAPs within a conditional maximum likelihood framework that accounts for the potential influence of unmeasured factors, jointly impacting farmers' perceptions and SAP adoption. We start with the basic probit regression model for SAP adoption, specified as follows:

$$
S A P_{i}=\beta_{0}+\beta_{1} \text { Percep }_{i}+\beta_{2} X_{i}+\varepsilon_{i}
$$

where $S A P_{i}$ is the binary variable of 1 , if the farmer $i$ adopts a certain SAP, and 0 otherwise; Percep $_{i}$ is a dummy indicator variable representing the farmer's perceptions on climate change; and $X_{i}$ is a vector of the observed characteristics believed to influence a farmer's adoption decision, including age, whether the farmer is the household head, gender, farming experience, years of completed education, number of farm workers, available income, access to electricity, distance to input markets, and region fixed effects.

Our baseline specification involves estimating Equation (1) through a standard probit regression. However, a failure to control for the potential endogeneity bias associated with the perceptions of the farmer, might result in inconsistent estimates. This endogeneity might arise due to some unobserved (to the researcher) characteristics, that might drive farmers to perceive climate change in a certain way, and this also influences the adoption of particular SAPs. For example, some farmers might possess a superior knowledge on the changes in climate simply because they are more knowledgeable than their counterparts. The knowledgeable farmers might acquire such information from agricultural extension officers or might be more educated than their counterparts.

To produce more credible estimates of the impact of the perceptions of farmers on the adoption of SAPs, we seek to estimate the following system of equations:

$$
\begin{gathered}
S A P_{i}=\beta_{0}+\beta_{1} \text { Percep }_{i}+\beta_{2} X_{i}+u_{i} \\
\text { Percep }_{i}=\alpha_{0}+\alpha_{1} Z+\alpha_{2} X_{i}+\varepsilon_{i}
\end{gathered}
$$


where $Z$ is a vector of instrumental variables thought to strongly influence the perceptions of farmers, and not the adoption of SAPs. These variables include memberships to community groups, contact with agricultural extension officers, access to electricity, education, and ownership of a radio. Equations (2) and (3) are simultaneously estimated through conditional maximum likelihood methods with heteroscedasticity-robust standard errors [50]. The identification of Equation (3) is ensured by the exclusion of the instrumental variables (Z) from Equation (2). This estimation strategy has been found to be more efficient than typical two-stage estimation procedures [51,52]. The system of equations is estimated using Stata's conditional mixed process estimator (CMP) [53]. This method allows us to assess whether the correlation between the error terms in Equation (2) and (3) are equal to zero. The failure to reject this hypothesis implies the exogeneity of perceptions, and thus, a standard probit regression would suffice.

\subsection{Model Variables and Descriptive Statistics}

In Table 1, we report the variable measurement, description, and summary statistics (mean and standard deviations) for the variables used in our analysis. Within our sample, about $60 \%$ of farmers perceived that the climate had changed in the recent past. Of the respondents that believed climate had changed, about $23 \%$ believed that temperatures in the area had increased, while about $80 \%$ believed that rainfall had decreased. Regarding the use of SAPs, $31 \%$ of the sampled farmers were using grain legume rotations in their fields, $60 \%$ were using inorganic fertilizers, $14 \%$ were using compost manure, $86 \%$ owned some livestock, and $44 \%$ were using farmyard manure, while $43 \%$ were using green manure. Overall, the SAPs mean index within our sample was 2.8.

Table 1. Descriptive statistics and variable definitions $(n=312)$.

\begin{tabular}{|c|c|c|c|}
\hline Variable & Variable Definitions and Measurement & Mean & SD \\
\hline Climate_change & $\begin{array}{l}\text { Binary variable }=1 \text { if farmer thinks that either temperature or rainfall patterns } \\
\text { have changed; } 0 \text { otherwise }\end{array}$ & 0.609 & 0.489 \\
\hline Temperature_increase & Binary variable $=1$ if farmer thinks that temperature has increased; 0 otherwise & 0.234 & 0.424 \\
\hline sap_index & $\begin{array}{l}\text { Sustainable agricultural practices index; a summation of all the 'yes' responses } \\
\text { if farmer adopted an SAP }\end{array}$ & 2.772 & 1.460 \\
\hline Rainfall increase & Binary variable $=1$ if farmer thinks that rainfall has increased; 0 otherwise & 0.196 & 0.397 \\
\hline sap_compost & Binary variable $=1$ if farmer adopted compost; 0 otherwise & 0.141 & 0.349 \\
\hline sap_livestock & Binary variable $=1$ if farmer owns livestock units; 0 otherwise & 0.859 & 0.349 \\
\hline sap_farmyard manure & Binary variable $=1$ if farmer adopted farm yard manure; 0 otherwise & 0.436 & 0.497 \\
\hline sap_green manure & Binary variable $=1$ if farmer adopted green manure; 0 otherwise & 0.429 & 0.496 \\
\hline respondent_hhead & Binary variable $=1$ if farmer is the household head; 0 otherwise & 0.647 & 0.479 \\
\hline respondent_male & Binary variable $=1$ if farmer is male; 0 otherwise & 0.830 & 0.376 \\
\hline laborforce & Number of household members who provide labor in the fields & 3.288 & 1.807 \\
\hline seed_expenditure & Binary variable $=1$ if farmer spent at least $\$ 1$ US on inputs (seeds); 0 otherwise & 0.067 & 0.251 \\
\hline livestock_number & Number of livestock units owned by the farmer & 1.457 & 4.093 \\
\hline Distance to input market & $\begin{array}{l}\text { Binary variable }=1 \text { if the distance to the nearest input/output market is } 10 \mathrm{~km} \\
\text { or more; } 0 \text { otherwise }\end{array}$ & 18.989 & 22.223 \\
\hline logarithm_landsize & Logarithm of land size & 1.930 & 0.902 \\
\hline community_membership & Binary variable $=1$ if farmer is a member to any community group; 0 otherwise & 0.340 & 0.474 \\
\hline extension_contact & $\begin{array}{l}\text { Binary variable }=1 \text { if farmer has contact with agriculture extension officers; } \\
0 \text { otherwise }\end{array}$ & 0.558 & 0.497 \\
\hline electricity & Binary variable $=1$ if farmer has electricity; 0 otherwise & 0.074 & 0.262 \\
\hline cellphone & Binary variable $=1$ if farmer has a cellphone; 0 otherwise & 0.426 & 0.495 \\
\hline radio & Binary variable $=1$ if farmer owns a radio; 0 otherwise & 0.609 & 0.489 \\
\hline
\end{tabular}

Notes: SAP: sustainable agricultural practices; SD: Standard Deviation.

Concerning household demographics, $65 \%$ of the sample respondents were household heads and $83 \%$ of them were male farmers. The mean household head age was about 47 years and the mean 
number of years of farming experience within the sample was 20. Moreover, sampled respondents had, on average, five years of formal schooling and about $87 \%$ of them had to farm as their main occupation. On average, each household had at least three members which were fit to provide labor in the fields, at the time of the survey.

Regarding resources and access to information, our descriptive statistics reveal that only $7 \%$ of the farmers spent at least \$1 US on purchased seed, and on average, each farmer owned about 1.5 livestock units. Moreover, only $7 \%$ of the respondents had access to electricity, $43 \%$ owned functional mobile cell phones, and $61 \%$ owned a functional radio at the time of the survey. Also, about $19 \%$ of the respondents travelled more than $10 \mathrm{~km}$ to the nearest input/output market. Membership to community groups was $34 \%$, and contact with extension agents was around $56 \%$. The mean log land size was found to be 1.93. Our sample distribution is made up of $49 \%$ of respondents from the central province of Malawi, $25 \%$ from the eastern province of Zambia, and 26\% from the Tete province of Mozambique.

\section{Results}

\subsection{Climate Change Perceptions and Use of SAPS}

In Table 2, we relate climate change perceptions to the use of SAPs within our sample. Perceptions on changes in temperature or rainfall, temperature alone, and rainfall alone, were matched with the use of SAPs, to include the use of grain-legume rotations, use of inorganic fertilizers, use of compost manure, ownership of some livestock units, use of farmyard manure, and green manuring in crop production. The table presents the descriptive statistics of this study.

Table 2. Descriptive statistics by perceptions on climate change.

\begin{tabular}{ccccccc}
\hline \multirow{2}{*}{ Variables } & \multicolumn{2}{c}{ Climate Change $(\boldsymbol{n}=\mathbf{1 3 4})$} & \multicolumn{2}{c}{ Temp Increased $(\boldsymbol{n = 7 3 )}$} & \multicolumn{2}{c}{ Rain Increase $(\boldsymbol{n}=\mathbf{6 1})$} \\
\cline { 2 - 6 } & Sum & Mean & Sum & Mean & Sum & Mean \\
\hline sap_legumes & 42 & 0.313 & 33 & 0.452 & 9 & 0.148 \\
sap_inorganic fertilizers & 82 & 0.612 & 47 & 0.644 & 35 & 0.574 \\
sap_compost & 17 & 0.127 & 12 & 0.164 & 5 & 0.082 \\
sap_livestock & 118 & 0.881 & 64 & 0.877 & 54 & 0.885 \\
sap_farm yard manure & 59 & 0.440 & 34 & 0.466 & 25 & 0.410 \\
sap_green manure & 54 & 0.403 & 30 & 0.411 & 24 & 0.393 \\
\hline
\end{tabular}

Overall, the results in Table 2 show that higher proportions of farmers who believed that the climate has changed, were found to be using SAPs in the form of inorganic fertilizers, grain legume rotations, farmyard manure, and green manuring. Besides, a higher proportion of them owned some livestock units. However, it is important to note that the results in Table 2 reflect mere associations and therefore need to be interpreted with caution. We cannot determine the impact of perceptions on the use of SAPs from the results in Table 2, and hence, we refer to Tables 3 and 4 to ascertain the influence of perceptions on the use of SAPs by smallholder farmers in the Chinyanja Triangle.

Table 3. The impact of climate change perceptions on the adoption of individual SAPs.

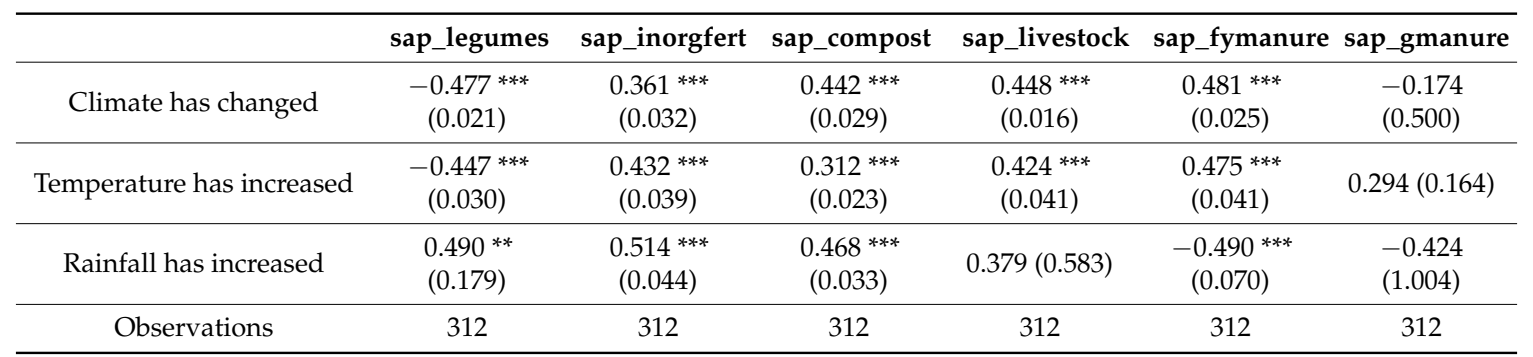

Notes: ${ }^{* *}$ significant at $1 \%,{ }^{* *}$ significant at $5 \%$, and ${ }^{*}$ significant at $10 \%$. Reported are marginal probability effects (ME) and their heteroskedasticity-robust standard errors shown in parentheses. 
Table 4. The impact of climate change perceptions on the index of SAPs adoption.

\begin{tabular}{ccccc}
\hline & \multicolumn{2}{c}{ OLS Estimates } & \multicolumn{2}{c}{ Maximum Likelihood Estimates } \\
\hline Variables & Coefficient & SE & Coefficient & SE \\
\hline Climate has changed & -0.044 & $(0.139)$ & $-1.705^{* * *}$ & $(0.437)$ \\
Temperature has increased & -0.219 & $(0.168)$ & 0.708 & $(0.535)$ \\
Rainfall has increased & 0.132 & $(0.162)$ & $1.839^{* * *}$ & $(0.321)$ \\
Observations & 312 & & 312 & \\
\hline
\end{tabular}

Notes: ${ }^{* * *}$ significant at $1 \%,{ }^{* *}$ significant at $5 \%$, and ${ }^{*}$ significant at $10 \%$. OLS: Ordinary Least Squares regression. Heteroskedasticity-robust standard errors (SE) in parentheses.

\subsection{Impact of Perceptions on the Use of SAPs}

To ascertain the impact of perceptions on the adoption and use of SAPs in crop production, we estimate a system of Equations (2) and (3), using a conditional mixed process that corrects for possible endogeneity associated with the perceptions decision. Precisely, we estimate the effect of climate change perceptions on the adoption of individual SAPs (results reported in Table 3), and also the effect of climate change perceptions on the index of SAP adoption. In estimating the impact of perceptions on SAPs, we control for various factors that are unique to individuals, including; binary indicator variables: head of household, the gender of the household head, whether the farmer is a full-time farmer, seed expenditures, access to electricity, and province fixed effects. We also included other controls for the farmer's age, farming experience, years of education, the number of farm workers, the logarithm of the land size, the distance to input market, and the number of livestock units owned by the farmer. Results for the factors which we controlled for (that can act as drivers of perceptions) are not shown in this manuscript, as our focus is mainly on the impact of the perceptions.

We report the impact results in Tables 3 and 4. Perceptions of climate change were found to have a significant effect on the use of individual SAPs, including; the use of grain legume rotations, use of inorganic fertilizers, use of compost manure, ownership of livestock units, and use of farmyard manure. Precisely, general climate change perceptions were found to have a significant adverse effect on the use of grain legume rotations, and a significant positive effect on the use of inorganic fertilizers, compost manure, ownership of livestock units, and use of farmyard manure. Perceptions on temperature increase were only found to have similar effects as the general perception that climate has changed. However, perceptions on rainfall increase were only found to have significant positive effects on the use of grain legume rotations, use of inorganic fertilizers, use of compost manure, and a significant adverse effect on the use of farmyard manure.

In Table 4, we report results on the impact of perceptions on the overall use of SAPs on the farm (measured by an index of SAPs adoption). Results show that climate change perceptions have a significant impact on the use of SAPs at a household level. The perception that rainfall had increased had a positive and meaningful impact on the overall use of SAPs at the farm level. The Ordinary Least Squares (OLS) regression estimates in Table 4 are from a regression model that ignores the potential endogeneity bias of perceptions. The OLS estimates indicate no significant effect of perceptions on the index of SAP adoption. However, the maximum likelihood estimates found after controlling for potential selectivity bias associated with farmers' perceptions, show the significant effect of climate change perceptions on the index of SAP adoption. The observation indicates that the failure to account for the potential endogeneity bias significantly biases the results, and potentially over- or underestimates the effects of perceptions on the index of SAP adoption.

Our results indicate that farmers' perceptions on climate change have a significant influence on the use of SAPs at the farm level. Moreover, different perceptions on changing climate variables, such as temperature and rainfall, can also have different effects on the use of individual SAPs and the overall level of SAP use at a farm level. 


\section{Discussion}

The main message obtained from our results is that climate change perceptions held by smallholder farmers can have a significant influence on the use of SAPs at the farm level. Farmers can respond through the adoption of SAPs, or by at least altering the level of already adopted SAPs, depending on what they think about changes in climatic variables, such as precipitation and temperature. Broadly, this finding could be explained by the observation that farmers adjust their adoption decisions, depending on their perceptions on the climate [28,30,35], in order to diminish the associated impacts of the changes on their farming enterprises. Results also concur with Dessai et al. [54], who asserted that, with various perceptions on changing climate, farmers anticipate the associated insecurities and thus adopt the relevant SAPs [54].

From our results, we found that perceptions on climate change (both temperature and rainfall change) and temperature increase, only have a significant positive effect on the ownership of livestock units at the household level. This finding is likely a result of the point that, when farmers perceive the possibility of extreme events, such as temperature increases, which threaten their crop production, they respond by seeking some form of insurance to diversify their livelihoods through keeping livestock units at the farm. In the case of total crop failure, they can resort to livestock sales (especially small livestock) for income. This finding partly corroborates the farming systems common in the Chinyanja Triangle. Moreover, given that some parts of the Chinyanja Triangle region are dry/semi-arid, and that farmers are well known to resort to livestock for survival during drought years [40,55], this finding is not surprising. Moreover, other studies in the region have found that livestock sales are a common strategy used for coping with drought $[56,57]$. Climate change perceptions were also found to have an impact on the use of SAPs in the form of ISFM (use of inorganic fertilizers, compost manure, and farmyard manure) at the farm level. This finding is possibly explained by the fact that, when farmers perceive climatic changes, they anticipate poor yields in the future, and hence, they may try to boost their current production by using productivity improving inputs to guard against future adverse impacts from climate change.

Moreover, general climate change perceptions and perceptions on increasing temperatures were found to have a significant adverse effect on the use of grain legume rotations, while a perceived increase in rainfall had a significant positive impact on the use of grain legume rotations. This finding could imply that, as temperatures rise, farmers anticipate a high aridity, which may result in water shortages for their rain-fed crops. Knowing this, smallholder farmers may be discouraged to practice grain legume rotations, as they may prioritize cereal production and other drought-tolerant crops such as cassava in each season, to boost their food stock. As stated in Amede et al. [40], the cereal basket common in the Chinyanja Triangle region includes maize (the main staple cereal), sorghum, and millet, of which sorghum and millet are more resistant to aridity. However, when they anticipate rainfall increase, they may be encouraged to practice grain legume rotations, as moisture availability can improve the effectiveness of crop rotations, and hence, its benefits to farming. Also, perceived rainfall increases were found to have a significant positive effect on the index of SAP adoption. The results confirm the correlation between farmers' perceptions on changing climate and the use of SAPs.

It is, however, important to note that the relationship between farmers' climate perceptions and the response undertaken by farmers in their farming activities, is not always a simple one [58]. According to Broadhead and Howard [59], understanding the relationships requires documenting gathered climatic knowledge, to provide a platform for decision making. With more accumulated climatic knowledge, farmers will have a greater understanding of the relationship between climate change and variability impacts, and necessary practices that they can adopt as adaptation and mitigation strategies [60]. The relationship between a farmer's climate change perceptions and adaptation options can even be further complicated, since perceptions regarding rainfall patterns do change over time. For example, the perceptions on rainfall can be driven by perceived changes in other climatic variables, such as temperature or precipitation [61]. This observation suggests that farmers with a low adaptive capacity, limited information, and skills to perceive changes accurately, may respond less (i.e., no significant 
change in their use of SAPs), when compared to more informed farmers. Since farmer perceptions and adaptation responses are not linear and obvious, our results can be interpreted as associations applicable to the sample of farmers in the Chinyanja Triangle area, and thus, may not be generalizable to other contexts or regions. Nevertheless, the results can be very useful considering the importance and accuracy of linking adaptation options for smallholder farmers with their understanding of climate-related changes [27-29].

This paper is not without its limitations. First, from a methodological standpoint, though we try to adopt an econometric strategy that accounts for the inherent selectivity bias associated with the farmer perception decision, our estimates may still be minimally biased. Second, given the difficulty in finding very good instruments, our choice of instrumental variables for identifying the SAP equation might be subject to scrutiny. However, given that the joint maximum likelihood framework we adopt does not strictly require that we include the instrumental variables for identification, we added a set of variables as instruments, as is customary in the studies of this nature. Thus, our analysis still provides validly credible estimates. Lastly, as is well known, the use of cross-sectional data in itself is associated with several limitations, including the failure to account for any dynamics associated with the adoption of SAPs and the formulation of perceptions. In addition, the use of cross-sectional data limits us in our capacity to interpret our estimates as representing causality. Despite the noted concerns, our analysis enriches our understanding of the associations between farmer perceptions regarding climate change and the adoption of sustainable agricultural practices in the Chinyanja Triangle area.

\section{Conclusions and Policy Implications}

We analyzed the linkages between smallholder farmers' perceptions and climate adaptations, using representative data gathered from selected sites within the Chinyanja Triangle area, found in southern Africa. Our results show some important linkages between farmers' perceptions regarding climate change and the adoption of sustainable agricultural practices. Particularly, we found that perceptions on climate change are linked to the adoption of grain legume rotations, inorganic fertilizers, ownership of livestock units, farmyard manure, and green manuring. The maximum likelihood estimates controlling for the selectivity bias of perceptions also show that climate change perceptions have a significant influence on both individuals, and the overall use of SAPs, at the farm level. Thus, we conclude that farmer perceptions ceteris paribus have an impact on the use of SAPs at the farm level. Smallholder farmers in the Chinyanja Triangle region are experiencing climate change (rainfall and temperature changes) and responding to these changes through alterations in the adoption and use of sustainable agricultural practices. Previous studies, for example [35,36,57,62,63], have also linked farmer perceptions and climatic action. Findings from these studies advocate improved adaptation planning at the local level, through the incorporation of local level perceptions regarding climatic irregularities.

The findings here suggest that perceptions on climate can be very helpful for researchers, policy makers, development partners, and other stakeholders concerned with climate change adaptation in smallholder farming communities. Understanding climate change perceptions and the linkages between perceptions and the use of sustainable agricultural practices, is important for public policy targeted at shaping adaptation options for smallholder farmers. Moreover, a lucid comprehension of smallholder farmers' views on climate change and their connection to SAPs, might provide viable and sustainable strategies to improve the cohesion between strategies meant to promote a wider adoption of climate adaptation practices (technologies and methods) and the actual rate of adoption. The promotion of SAPs as an adaptation strategy for the ever-changing climate can also be improved through a clear understanding of climate change perceptions held by farmers. This is because, if farmers perceive substantial variations in the climate, it will be easy for them to understand the dangers which can, therefore, push them to find ways of guarding against the adverse effects, as observed in this study. Our results suggest that targeted interventions offer adaptations to climate change, through the adoption and use of SAPs in smallholder farming communities; concerned parties (government, the 
private sector, development partners, etc.) first ought to understand, and possibly match, a farmer's perceptions and experiences with scientific evidence of climate change. The failure to synchronize a farmer's understanding of climate change and targeted interventions can undermine the effectiveness of interventions. The success of various stakeholders concerned with improving rural livelihoods in the wake of climatic changes, hinges upon how the society builds its understanding of the problem, and not merely what the scientific community's technical knowledge provides [36,64]. Moreover, given that adaptation processes are primarily social and involve drawing on collective action (i.e., collective social resources) [65], capturing individual farmers' stock of social capital (proxied by their knowledge and awareness on climate change issues) might be an important input to the climate change adaptation policy process. This is possible, as Adger [15] underlined that the effective adaptation and pliability of an individual entity to the effects of climate change is not a self-contained process; rather, it is a social one involving the interdependence of agents through their interactions with each other $[15,65]$. The focus of adaptation policy in smallholder farming should, therefore, include inputs from a wide array of stakeholders, including the experiences and understanding of climatic variability and change in the different sectors of the farming community, in addition to the scientific evidence and expert knowledge available.

Author Contributions: C.M.: Conceived and formulated the research idea and played a leading role in drafting the literature review, empirical analysis, writing, interpretation and discussion of the results. M.M.: Participated in the data analysis, interpretation and discussion of the results. N.M.: Participated in revising and editing of the manuscript. All authors proof read and approved the final version of the manuscript.

Conflicts of Interest: The authors declare no conflict of interest.

\section{References}

1. Corina Hoppner, and Lorraine E. Whitmarsh. "Public Engagement in Climate Action: Policy and Public Expectations." In Engaging the Public with Climate Change. Behavior Change and Communication. Edited by Lorraine E. Whitmarsh, Saffron O'Neill and Irene Lorenzoni. London: Earthscan, 2011, pp. 47-65.

2. Nick Pidgeon, and Baruch Fischhoff. "The Role of Social and Decision Sciences in Communicating Uncertain Climate Risks." Nature Climate Change 1 (2011): 35-41. [CrossRef]

3. Juliet Pietsch, and Ian McAllister. "'A Diabolical Challenge': Public Opinion and Climate Change Policy in Australia." Environmental Politics 19 (2010): 217-36. [CrossRef]

4. Intergovernmental Panel on Climate Change (IPCC). Climate Change 2014: Impacts, Adaptation, and Vulnerability. Part A: Global and Sectoral Aspects. Contribution of Working Group II to the Fifth Assessment Report of the Intergovernmental Panel on Climate Change. Cambridge and New York: Cambridge University Press, 2014.

5. Emma Archer, Elijah Mukhala, Sue Walker, Maxx Dilley, and Kennedy Masamvu. "Sustaining Agricultural Production and Food Security in Southern Africa: An Improved Role for Climate Prediction?" Climatic Change 83 (2007): 287-300. [CrossRef]

6. Aslihan Arslan, Nancy McCarthy, Leslie Lipper, Solomon Asfaw, and Andrea Cattaneo. "Adoption and Intensity of Adoption of Conservation Farming Practices in Zambia." Agriculture, Ecosystems and Environment 187 (2014): 72-86. [CrossRef]

7. IPCC. "Summary for Policymakers." In Climate Change 2014: Impacts, Adaptation, and Vulnerability. Part A: Global and Sectoral Aspects. Contribution of Working Group II to the Fifth Assessment Report of the Intergovernmental Panel on Climate Change. Edited by Christopher B. Field, Vicente R. Barros, David Jon Dokken, Katharine J. Mach, Michael D. Mastrandrea, T. Eren Bilir, Monalisa Chatterjee, Kristie L. Ebi, Yuka Otsuki Estrada, Robert C. Genova and et al. Cambridge and New York: Cambridge University Press, 2014, pp. 1-32.

8. Jules N. Pretty, Andrew D. Noble, Deborah Bossio, John Dixon, Rachel E. Hine, Frits W. T. Penning de Vries, and James I. L. Morison. "Resource-Conserving Agriculture Increases Yields in Developing Countries." Environmental Science \& Technology 40 (2006): 1114-19. [CrossRef]

9. Bouba Traore, Marc Corbeels, Mark T. van Wijk, Mariana C. Rufino, and Ken E. Giller. “Effects of Climate Variability and Climate Change on Crop Production in Southern Mali." European Journal of Agronomy 49 (2013): 115-25. [CrossRef] 
10. Bouba Traore, Mark T. Van Wijk, Katrien Descheemaeker, Marc Corbeels, Mariana C. Rufino, and Ken E. Giller. "Climate Variability and Change in Southern Mali: Learning from Farmer Perceptions and on-Farm Trials." Experimental Agriculture 51 (2015): 615-34. [CrossRef]

11. Eric O. Odada, Robert J. Scholes, Kevin Noone, Cheikh Mbow, and Washington O. Ochola, eds. A Strategy for Global Environmental Change Research in Africa: Science Plan and Implementation Strategy. Stockholm: IGBP Secretariat, 2008.

12. M. V. K. Sivakumar, H. P. Das, and O. Brunini. "Impacts of Present and Future Climate Variability and Change on Agriculture and Forestry in the Arid and Semi-Arid Tropics." Climatic Change 70 (2005): 31-72. [CrossRef]

13. Rattan Lal, Bal Ram Singh, Dismas L. Mwaseba, David Kraybill, David O. Hansen, and Lars Olav Eik, eds. Sustainable Intensification to Advance Food Security and Enhance Climate Resilience in Africa. Cham: Springer International Publishing, 2015.

14. W. Neil Adger, Saleemul Huq, Katrina Brown, Declan Conway, and Mike Hulme. "Adaptation to Climate Change in the Developing World." Progress in Development Studies 3 (2003): 179-95. [CrossRef]

15. W. Neil Adger. "Social Capital, Collective Action, and Adaptation to Climate Change." Economic Geography 79 (2003): 387-404. [CrossRef]

16. K. Waha, C. Müller, Alberte Bondeau, J. P. Dietrich, Pradeep Kurukulasuriya, Jens Heinke, and H. Lotze-Campen. "Adaptation to Climate Change through the Choice of Cropping System and Sowing Date in Sub-Saharan Africa." Global Environmental Change 23 (2013): 130-43. [CrossRef]

17. Miguel A. Altieri, Marcos A. Lana, Henrique V. Bittencourt, André S. Kieling, Jucinei J. Comin, and Paulo E. Lovato. "Enhancing Crop Productivity Via Weed Suppression in Organic No-Till Cropping Systems in Santa Catarina, Brazil." Journal of Sustainable Agriculture 35 (2011): 855-69. [CrossRef]

18. Kayode Arimi. "Determinants of Climate Change Adaptation Strategies Used by Rice Farmers in Southwestern, Nigeria." Journal of Agriculture and Rural Development in the Tropics and Subtropics (JARTS) 115 (2014): 91-99.

19. Mark Davies, Bruce Guenther, Jennifer Leavy, Tom Mitchell, and Thomas Tanner. "Climate Change Adaptation, Disaster Risk Reduction and Social Protection: Complementary Roles in Agriculture and Rural Growth?" IDS Working Papers 320 (2009): 1-37. [CrossRef]

20. Ephraim Nkonya, Frank Place, Edward Kato, and Majaliwa Mwanjololo. “Climate Risk Management through Sustainable Land Management in Sub-Saharan Africa." In Sustainable Intensification to Advance Food Security and Enhance Climate Resilience in Africa. Edited by Rattan Lal, Bal Ram Singh, Dismas L. Mwaseba, David Kraybill, David O. Hansen and Lars Olav Eik. Cham: Springer International Publishing, 2015, pp. 75-111.

21. Ellen Wall, and Barry Smit. "Climate Change Adaptation in Light of Sustainable Agriculture." Journal of Sustainable Agriculture 27 (2005): 113-23. [CrossRef]

22. David Tilman, Kenneth G. Cassman, Pamela A. Matson, Rosamond Naylor, and Stephen Polasky. "Agricultural Sustainability and Intensive Production Practices." Nature 418 (2002): 671-77. [CrossRef] [PubMed]

23. Bernard Vanlauwe, André Bationo, J. Chianu, Ken E. Giller, Roel Merckx, U. Mokwunye, Omo Ohiokpehai, Pieter Pypers, R. Tabo, and Keith D. Shepherd. "Integrated Soil Fertility Management Operational Definition and Consequences for Implementation and Dissemination." Outlook on Agriculture 39 (2010): 17-24. [CrossRef]

24. Bernard Vanlauwe, J. Wendt, K.E. Giller, M. Corbeels, B. Gerard, and C. Nolte. "A Fourth Principle Is Required to Define Conservation Agriculture in Sub-Saharan Africa: The Appropriate Use of Fertilizer to Enhance Crop Productivity." Field Crops Research 155 (2014): 10-13. [CrossRef]

25. Irene Lorenzoni, Sophie Nicholson-Cole, and Lorraine Whitmarsh. "Barriers Perceived to Engaging with Climate Change among the Uk Public and Their Policy Implications." Global environmental change 17 (2007): 445-59. [CrossRef]

26. Janet K. Swim, Susan Clayton, and George S. Howard. "Human Behavioral Contributions to Climate Change: Psychological and Contextual Drivers." American Psychologist 66 (2011): 251-64. [CrossRef] [PubMed]

27. Elisabeth Simelton, Claire H. Quinn, Nnyaladzi Batisani, Andrew J. Dougill, Jen C. Dyer, Evan D.G. Fraser, David Mkwambisi, Susannah Sallu, and Lindsay C. Stringer. "Is Rainfall Really Changing? Farmers' Perceptions, Meteorological Data, and Policy Implications." Climate and Development 5 (2013): 123-38. [CrossRef]

28. Temesgen Tadesse Deressa, Rashid M. Hassan, and Claudia Ringler. "Perception of and Adaptation to Climate Change by Farmers in the Nile Basin of Ethiopia." The Journal of Agricultural Science 149 (2011): 23-31. [CrossRef] 
29. David Maddison. "The Perception of and Adaptation to Climate Change in Africa." CEEPA Discussion Paper no. 10, Centre for Environmental Economics and Policy in Africa, University of Pretoria, Hatfield, UK, 2006.

30. David S. G. Thomas, Chasca Twyman, Henny Osbahr, and Bruce Hewitson. "Adaptation to Climate Change and Variability: Farmer Responses to Intra-Seasonal Precipitation Trends in South Africa." Climatic Change 83 (2007): 301-22. [CrossRef]

31. Richard J. Bord, Robert E. O'Connor, and Ann Fisher. "In What Sense Does the Public Need to Understand Global Climate Change? " Public Understanding of Science 9 (2000): 205-18. [CrossRef]

32. Stuart Capstick, Lorraine Whitmarsh, Wouter Poortinga, Nick Pidgeon, and Paul Upham. "International Trends in Public Perceptions of Climate Change over the Past Quarter Century." Wiley Interdisciplinary Reviews: Climate Change 6 (2015): 35-61.

33. Christian A. Klöckner. "A Comprehensive Model of the Psychology of Environmental Behaviour-A MetaAnalysis." Global Environmental Change 23 (2013): 1028-38. [CrossRef]

34. Christina Tobler, Vivianne H. M. Visschers, and Michael Siegrist. "Addressing Climate Change: Determinants of Consumers' Willingness to Act and to Support Policy Measures." Journal of Environmental Psychology 32 (2012): 197-207. [CrossRef]

35. Ole Mertz, Cheikh Mbow, Anette Reenberg, and Awa Diouf. "Farmers' Perceptions of Climate Change and Agricultural Adaptation Strategies in Rural Sahel." Environmental Management 43 (2009): 804-16. [CrossRef] [PubMed]

36. Nicholas Wiid, and Gina Ziervogel. "Adapting to Climate Change in South Africa: Commercial Farmers' Perception of and Response to Changing Climate." South African Geographical Journal 94 (2012): 152-73. [CrossRef]

37. Jens Hesselbjerg Christensen, Bruce Hewitson, Aristita Busuioc, Anthony Chen, Xuejie Gao, R. Held, Richard Jones, Rupa Kumar Kolli, W. K. Kwon, and René Laprise, et al. "Regional Climate Projections." In Climate Change, 2007: The Physical Science Basis. Contribution of Working Group I to the Fourth Assessment Report of the Intergovernmental Panel on Climate Change. Edited by Susan Solomon, Dahe Qin, Martin Manning, Melinda Marquis, Kristen Averyt, Melinda M.B. Tignor, Henry LeRoy Miller Jr. and Zhenlin Chen. Cambridge and New York: Cambridge University Press, 2007, pp. 847-940.

38. Edward Clay, Louise Bohn, Enrique Blanco de Armas, Singand Kabambe, and Hardwick Tchale. "Malawi and Southern Africa Climatic Variability and Economic Performance." Disaster risk management working paper series no. 7, The World Bank, Washington, DC, USA, 2003.

39. Leslie Lipper, Philip Thornton, Bruce M. Campbell, Tobias Baedeker, Ademola Braimoh, Martin Bwalya, Patrick Caron, Andrea Cattaneo, Dennis Garrity, Kevin Henry, and et al. “Climate-Smart Agriculture for Food Security." Nature Climate Change 4 (2014): 1068-72. [CrossRef]

40. Tilahun Amede, Lulseged Tamene Desta, Dave Harris, Fred Kizito, and Xueliang Cai. “The Chinyanja Triangle in the Zambezi River Basin, Southern Africa: Status of, and Prospects for, Agriculture, Natural Resources Management and Rural Development." WLE Research for Development (R4D) Learning Series 1, International Water Management Institute, Pretoria, UK, 2014.

41. Mariam A. T. J. Mapila, J. Njuki, Robert J. Delve, Shamie Zingore, and Josephine Matibini. “Determinants of Fertiliser Use by Smallholder Maize Farmers in the Chinyanja Triangle in Malawi, Mozambique and Zambia." Agrekon 51 (2012): 21-41. [CrossRef]

42. Powell Mponela, Lulseged Tamene, Gift Ndengu, Ruth Magreta, Job Kihara, and Nelson Mango. “Determinants of Integrated Soil Fertility Management Technologies Adoption by Smallholder Farmers in the Chinyanja Triangle of Southern Africa." Land Use Policy 59 (2016): 38-48. [CrossRef]

43. Karen Frenken, and Faurès Jean-Marc. Irrigation Potential in Africa: A Basin Approach. Rome: Food \& Agriculture Organization (FAO), 1997.

44. Marike Myburgh, and Jerry Brown. The Potential of Information and Communication Technology as an Enabler for Agricultural and Community Development in the Chinyanja Triangle. Dennesig: Agribusiness in Sustainable Natural African Plant Products (ASNAPP), 2006.

45. Aaron J. M. Russell, Patrick A. Grötz, Simone K. Kriesemer, and Diemuth E. Pemsl. Recommendation Domains for Pond Aquaculture. Country Case Study: Development and Status of Freshwater Aquaculture in Malawi. Penang: The World Fish Center, 2008. 
46. Michael R. Rahm, and Wallace E. Huffman. "The Adoption of Reduced Tillage: The Role of Human Capital and Other Variables." American Journal of Agricultural Economics 66 (1984): 405-13. [CrossRef]

47. Workeneh Negatu, and Ashok Parikh. "The Impact of Perception and Other Factors on the Adoption of Agricultural Technology in the Moret and Jiru Woreda (District) of Ethiopia." Agricultural Economics 21 (1999): 205-16. [CrossRef]

48. Akinwumi A. Adesina, and Jojo Baidu-Forson. "Farmers' Perceptions and Adoption of New Agricultural Technology: Evidence from Analysis in Burkina Faso and Guinea, West Africa." Agricultural Economics 13 (1995): 1-9. [CrossRef]

49. Akinwumi A. Adesina, and Moses M. Zinnah. "Technology Characteristics, Farmers' Perceptions and Adoption Decisions: A Tobit Model Application in Sierra Leone." Agricultural Economics 9 (1993): 297-311. [CrossRef]

50. Jeffrey M. Wooldridge. Econometric Analysis of Cross Section and Panel Data. Cambridge: MIT Press, 2002.

51. Edward C. Norton, Richard C. Lindrooth, and Susan T. Ennett. "Controlling for the Endogeneity of Peer Substance Use on Adolescent Alcohol and Tobacco Use." Health Economics 7 (1998): 439-53. [CrossRef]

52. Douglas Rivers, and Quang H. Vuong. "Limited Information Estimators and Exogeneity Tests for Simultaneous Probit Models." Journal of Econometrics 39 (1988): 347-66. [CrossRef]

53. David Roodman. "Fitting Fully Observed Recursive Mixed-Process Models with Cmp." Stata Journal 11 (2011): 159-206.

54. Suraje Dessai, W. Neil Adger, Mike Hulme, John Turnpenny, Jonathan Köhler, and Rachel Warren. “Defining and Experiencing Dangerous Climate Change." Climatic Change 64 (2004): 11-25. [CrossRef]

55. CGIAR Research Program on Water, Land and Ecosystems (WLE). "Chiefs in Chinyanja Triangle." Available online: https://www.youtube.com/watch?v=TX1b1a_64dM (accessed on 28 December 2016).

56. John Morton, and David Barton. "Destocking as a Drought-Mitigation Strategy: Clarifying Rationales and Answering Critiques." Disasters 26 (2002): 213-28. [CrossRef] [PubMed]

57. Lindsay C. Stringer, Jen C. Dyer, Mark S. Reed, Andrew J. Dougill, Chasca Twyman, and David Mkwambisi. "Adaptations to Climate Change, Drought and Desertification: Local Insights to Enhance Policy in Southern Africa." Environmental Science \& Policy 12 (2009): 748-65.

58. Christopher R. Bryant, Barry Smit, Michael Brklacich, Thomas R. Johnston, John Smithers, Quentin Chjotti, and Bhawan Singh. "Adaptation in Canadian Agriculture to Climatic Variability and Change." Climatic Change 45 (2000): 181-201. [CrossRef]

59. Lee-Anne Broadhead, and Sean Howard. “Deepening the Debate over 'Sustainable Science': Indigenous Perspectives as a Guide on the Journey." Sustainable Development 19 (2011): 301-11. [CrossRef]

60. Charmine E. J. Härtel, and Graeme I. Pearman. "Understanding and Responding to the Climate Change Issue: Towards a Whole-of-Science Research Agenda." Journal of Management E Organization 16 (2010): $16-47$.

61. Henny Osbahr, Peter Dorward, Roger Stern, and Sarah Cooper. "Supporting Agricultural Innovation in Uganda to Respond to Climate Risk: Linking Climate Change and Variability with Farmer Perceptions." Experimental Agriculture 47 (2011): 293-316. [CrossRef]

62. J. Gordon Arbuckle, Lois Wright Morton, and Jon Hobbs. "Farmer Beliefs and Concerns About Climate Change and Attitudes toward Adaptation and Mitigation: Evidence from Iowa." Climatic Change 118 (2013): 551-63. [CrossRef]

63. Architesh Panda. "Exploring Climate Change Perceptions, Rainfall Trends and Perceived Barriers to Adaptation in a Drought Affected Region in India." Natural Hazards 84 (2016): 777-96. [CrossRef]

64. Timothy McDaniels, Lawrence J. Axelrod, and Paul Slovic. "Perceived Ecological Risks of Global Change: A Psychometric Comparison of Causes and Consequences." Global Environmental Change 6 (1996): 159-71. [CrossRef]

65. Jordan W. Smith, Dorothy H. Anderson, and Roger L. Moore. "Social Capital, Place Meanings, and Perceived Resilience to Climate Change." Rural Sociology 77 (2012): 380-407. [CrossRef]

(C) 2017 by the authors. Licensee MDPI, Basel, Switzerland. This article is an open access article distributed under the terms and conditions of the Creative Commons Attribution (CC BY) license (http:/ / creativecommons.org/licenses/by/4.0/). 